\title{
Concentration-normalised electroanalytical assaying of exosomal markers
}

\author{
Qian Li, ${ }^{1}$ George K. Tofaris, ${ }^{2}$ Jason J. Davis ${ }^{1 *}$
}

${ }^{1}$ Department of Chemistry, Physical and Theoretical Chemistry Laboratory, University of Oxford, South Parks Road, Oxford, OX1 3QZ, United Kingdom

${ }^{2}$ Nuffield Department of Clinical Neurosciences, University of Oxford, John Radcliffe Hospital, Oxford, OX3 9DU, United Kingdom

*Corresponding author

Tel: +44 (0) 1865 275914. Email: jason.davis@chem.ox.ac.uk 


\section{Abstract}

Exosomes are both active in mediating intracellular communication and potentially present a potent cargo of disease biomarkers to an assay. The robust evaluation of exosomal markers could lead to a paradigm shift in clinical analysis and associated care. To date, much of this has been hindered by issues of sample preparation and assay signal-to-noise. We introduce here the use of ultrasensitive electrochemical impedance spectroscopy to quantify both external (tetraspanin) and internal (syntenin) exosome-specific markers. Associated exosome detection limits are $1.9 \times 10^{5}$ particles $\mathrm{mL}^{-}$

${ }^{1}$ (equiv. to $320 \mathrm{aM}$ or 9500 exosomes in $50 \mu \mathrm{L}$ ) for intact exosomes and $3-5$ picomolar for internal exosomal syntenin levels with almost five decades of linear dynamic range. Sample preparation can be carried out by simple fine filtering of cell conditioned medium prior to a non-NTA (nanoparticle tracking analysis) determined exosome concentration analysis, lysing and subsequent internal syntenin quantification. Such concentration normalised dual-marker analysis can be used to define 'analytical zones' in a manner which is then independent of absolute exosome concentration and sample preparation. 


\section{Introduction}

Exosomes are small extracellular vesicles $(30-100 \mathrm{~nm}$ in diameter) derived from all types of cells as part of a complex endosomal secretory pathway. ${ }^{1}$ These membrane-bound vesicles have generated increasing levels of interest, largely due to their mediating role in intracellular communication, physiological immune response and disease pathogenesis. ${ }^{2,3}$ As such these small vesicles potentially present a potent cargo of disease biomarkers. ${ }^{4,5}$ In recent years, for example, exosomes isolated from various cell lines and bodily fluids (including blood, saliva, urine and breast milk) have been extensively documented to demonstrate differential (when compared to healthy samples) mRNA, miRNA and protein expression in the case of pancreatic, ${ }^{6,7}$ prostate,,${ }^{8,9}$ bladder, ${ }^{10}$ ovarian ${ }^{11}$ and breast ${ }^{12}$ cancers. There is, then, considerable interest in developing diagnostic strategies capable of identifying specific exosomes and/or their components as a means of underpinning early diagnosis, disease stratification and monitoring response to treatment. ${ }^{2,7,11,13}$

Although extensive studies have identified a number of exosome-related protein markers consistently present in extracellular vesicles (EVs) generally, such as the tetraspanins (CD9, CD63 and CD81), flotillin, actin, heat shock proteins (Hsp60, Hsp70, Hsp90) or the major histocompatibility complex (MHC) class I and class II proteins, ${ }^{1,3}$ it has also become clear that cells secret different subtypes of EVs each encapsulating specific molecular markers. ${ }^{14,15}$ Recently, a comprehensive quantitative proteomic analysis of refined subpopulations of lysed vesicles isolated by ultracentrifugation identified that, among 241 proteins in small EVs co-enriched with tetraspanins (CD9, CD63 and CD81), syntenin-1 (a key regulator of exosome biogenesis, also known as MDA-9 or SDCBP) and TSG101 (an endosomal sorting complexe required for transport) represent distinct exosome-specific markers that represent 'bona fide' exosomes, ${ }^{15}$ an observation echoeing previous work by Jeppesen et al. who noted a high abundance of syntenin in smaller and/or less dense exosomes. ${ }^{14}$ In considering the natively heterogeneous characteristics of small EVs, this information not only provides a means of identifying 'bona fide' exosomes but also of normalising any subsequent content analysis for exosome concentration. 
Conventionally, exosomes are typically isolated by ultracentrifugation (UC) prior to analysis by Western blot (WB), enzyme-linked immunosorbent assay (ELISA) or mass spectrometry. ${ }^{14-16}$ These techniques both struggle to satisfy a convenient (sample preparation time is $4-5$ hours) ${ }^{17}$ and ultrasensitive analysis (usually low $\mathrm{nM}$ detection range). ${ }^{5}$ Although assay sensitivity can be increased through microfluidic integration or the use of metal-nanoparticle oxidation, extensive labelling protocols are required. ${ }^{9,18,19}$ Of the methods potentially available for the facile and label free analysis of exosomes, those based on optical plasmon resonance ${ }^{20,21}$ and nano-plasmonic assays ${ }^{5}$ have drawn attention. Although the latter has been reported to underpin a $670 \mathrm{aM}$ detection limit of exosomes using anti-CD63 decorated interfaces, to be effective specifically fabricated nanoarrays are required. Of the label free electroanalytical methods available, impedimetric analyses ${ }^{22,23}$ stands out in terms of experimental flexibility and sensitivity but has not, to the best of our knowledge, been prior applied to exosomal analysis.

The syntenin-1 protein has been consistently noted as being overexpressed in multiple human cancer cell lines, often in a manner which appears to scale with disease progression. ${ }^{24-27}$ Interestingly, raised syntenin levels have been reported in early stage Parkinson's disease patient sera-derived microvesicles in a mass spectroscopic analysis. ${ }^{28}$ Within this work, electrochemical impedance spectroscopy was applied to quantify both external (tetraspanin) and internal (syntenin) exosomespecific markers. Since the absolute quantification of any such markers will necessarily be a sensitive function of sample preparation and isolated exosome concentration (something which can vary over several orders of magnitude and from sample batch to batch $)^{29}$ we have additionally sought herein to normalise all exosomal syntenin quantification without any prior requirement for an ex situ NTA analysis and to also bypass the time consuming UC methods most typically applied to exosomal isolation. This was achieved through the convenient application of fine sample filtering then CD81 electroanalysis prior to lysis and a quantification of exosomal syntenin. Samples isolated from an embryonic kidney HEK293 cell line produced interfacial impedance changes upon intact exosome capture that are linear over five orders of magnitude particle numbers, with very low associated 
detection limits. We believe the approaches outlined lay a foundation for an in situ on-chip normalised sensitive electroanalysis of a range of exosomal markers in a convenient format.

\section{Experimental section}

\section{Chemical reagents}

All chemicals were of analytical grade and used without further purification. Potassium ferricyanide (III), Potassium ferrocyanide (II), 1-ethyl-3-(3- (dimethylamino)propyl) carbodiimide (EDC), Nhydroxysuccinimde (NHS), sodium dodecyl sulfate (SDS), Triton X-100 (TX), Tween-20 (T), Dulbecco's Modified Eagle's medium (DMEM), Hanks Balanced Salt Solution (HBSS), TrypsinEDTA, Penicillin-strptomycin and absolute ethanol (HPLC grade) were purchased from SigmaAldrich (Gillingham, UK) except polyethylene glycol thiol HS-(CH2)11-(EG)3-OCH2-COOH (PEGylated thiol) was from Prochimia Surfaces (Poland). All aqueous solutions were prepared with deionised water of resistivity not less than $18.2 \mathrm{M} \Omega \mathrm{cm}$ at $298 \mathrm{~K}$ (Millipore UHQ, Vivendi, UK).

\section{Protein samples}

Bovine serum albumin (BSA), fetal bovine serum (FBS) and human serum (from clotted human male whole blood, $40-90 \mathrm{mg} / \mathrm{ml}$ total protein) were purchased from Sigma-Aldrich. Anti-syntenin antibody [EPR8102] and anti-CD81 were purchased from Abcam; recombinant syntenin-1 (human SDCBP) was from Abnova. All protein samples were used as received without further purification and diluted in $0.22 \mu \mathrm{m}$ filtered PBS tablet buffer solutions (pH 7.4 at $25{ }^{\circ} \mathrm{C}$, Sigma-Aldrich) prior to receptor layer binding.

\section{Cell culture}

HEK293 cells (human embryonic kidney 293 cells) were grown in an incubator at $37{ }^{\circ} \mathrm{C}$ with $5 \%$ $\mathrm{CO}_{2}$. The cells were maintained in DMEM supplemented with $10 \%$ fetal bovine serum (FBS) and $1 \%$ Penicillin-Streptomycin and split regularly with Trypsin-EDTA. Three million cells were seeded into a T75 flask. After cell attachment, the medium was replaced with exosome-free serum in DMEM and incubated for 48 hours before harvesting the supernatant. The collected supernatant was centrifuged at 
$1200 \mathrm{x} \mathrm{g}$ for 5 mins and its supernatant further centrifuged at $1500 \mathrm{x} \mathrm{g}$ for 10 mins to eliminate cell debris. The supernatant was re-collected and aliquoted for further experiments.

\section{Exosome isolation}

Exosomes were isolated from cell conditioned medium through ultrafiltration via an in-house assembled device fitted with membrane filters of $800 \mathrm{~nm}, 200 \mathrm{~nm}$ and $100 \mathrm{~nm}$ in size (Nuclepore ${ }^{\mathrm{TM}}$ track etched filters, Whatman, GE Healthcare). Only the final filtrate was used throughout this study. Filtrates were prepared daily and characterised on the same day as preparation. Concentrated exosome samples were subjected to an ultracentrifugation (UC) process from the raw CCM samples. First centrifuge at $17,000 \mathrm{x}$ g for 15 minutes, then subjected to $160,000 \mathrm{x}$ g for 1 hour. The pellets were suspended in $25 \mu \mathrm{HBSS}$ for further analysis. Note that UC was used solely to generate samples with exosomes in the higher concentration limit. The majority of samples were prepared by ultrafiltration only, reducing preparation time to $<30$ mins.

\section{Nanoparticle tracking analysis (NTA)}

Exosome particles present in filtrate samples were analysed by a NanoSight NS500 system (Malvern Instruments Ltd., UK), configured with a $405 \mathrm{~nm}$ laser and a high-sensitivity sCMOS camera (OrcaFlash2.8, Hamamatsu C11440, NanoSight Ltd). Videos were collected and analysed using the NTA software (version 2.3, build 0025) with Camera Level set to 14 and detection threshhold at 5. All analysis carried out at a controlled temperature fixed at $23{ }^{\circ} \mathrm{C}$.

Each sample was diluted in particle-free PBS (Life Technologies Ltd). Approximately $20-40$ particles were in the field of view and a typical concentration was approximately $(5-12) \times 10^{8}$ particles/ml for each measurement. By monitoring the trajectory of exosome movement, particle number and size distribution were obtained from averaged measurements of 3 videos, each of 30 seconds duration. 


\section{Transmission electron microscopy (TEM)}

TEM was carried out via negative staining using a $1-3 \%$ solution of uranyl acetate ( $\mathrm{pH} 4.2$ to 4.5). Equal amount of $20 \mu \mathrm{L}$ of sample and stain were mixed and dropped onto a formvar grid for ca. $20 \mathrm{~s}$. Then the stain was filtered through a $0.22 \mu \mathrm{m}$ filter and allowed air dry.

\section{Au bead electrode preparation}

Small (see below) spherical gold beads were prepared by hydrogen flame annealing of high purity gold wire (dia. $0.5 \mathrm{~mm}, 99.9989 \%$, Advent Research Materials, UK) within a borosilicate glass capillary tube (bore size ca. $0.8 \mathrm{~mm}$, World Precision Instruments, UK) in generating glass sealed gold ball electrodes. Fabrication reproducibility was tested upon five heat annealing treatments and electroanalytical surface areas evaluated by analysis of the gold oxide reduction peak. Subsequently assessed surface area coefficients of variation (defined as the ratio of the standard deviation to the mean) were calculated to be $<1.6 \%$ and mean electroactive areas $0.049 \mathrm{~cm}^{2}$.

\section{Fabrication of receptor interface}

PEGylated SAMs were generated by immersion of cooled gold ball electrodes in $1 \mathrm{mM}$ ethanolic PEG thiol solution for 16 hours at room temperature in the dark. The terminal carboxyl groups were then activated with 1-ethyl-3-(3-(dimethylamino)propyl) carbodiimide (EDC, $0.4 \mathrm{M}$ ) and Nhydroxysuccinimide (NHS, $0.1 \mathrm{M}$ ) for 40 mins at room temperature, followed by antibody $(1 \mu \mathrm{M})$ immobilisation for $2 \mathrm{hrs}$ at $4{ }^{\circ} \mathrm{C}$. The interface was subsequently washed and immersed in a $0.1 \%$ BSA / PBS (w:v) solution for an additional 40 mins to deactivate any residual carboxylic groups and block sites of potential nonspecific adsorption. ${ }^{30}$

\section{Electrochemical impedance spectroscopy (EIS)}

Electrochemical measurements were recorded by using a PGSTAT12 potentiostat (Metrohm Autolab, Netherlands) with a standard three electrode configuration. Faradaic electrochemical impedance measurements were conducted in a redox probe containing $\left(1 \mathrm{mM}\right.$ of $\mathrm{K}_{3}\left[\mathrm{Fe}(\mathrm{CN})_{6}\right]$ and $\left.\mathrm{K}_{4}\left[\mathrm{Fe}(\mathrm{CN})_{6}\right]\right)$ 
PBS solution. Each analytical point was obtained ex-situ upon incubation in analyte solution for 30 mins and transferring back to the redox probe PBS. All measurements were performed under temperature controlled conditions within a water-jacketed flask at $\left(20 \pm 0.2^{\circ} \mathrm{C}\right)$.

The frequency response analyzer was applied across a frequency range of $(0.1-100 \mathrm{k}) \mathrm{Hz}$ with an RMS amplitude of $3 \mathrm{mV}$. Immittance function $(\operatorname{ImFs})$ analyses were employed in order to generate facile quantitative information. ${ }^{31}$ All $\operatorname{Im} F$ s are complex functions composed of their real $(\operatorname{Im} F)$ and imaginary $\left(\operatorname{Im} F^{\prime \prime}\right)$ parts and are derived from the $Z^{*}=Z^{\prime}+j Z^{\prime \prime}$ at each specific frequency. By analysing the components of real, imaginary, modulus $(|\operatorname{Im} F|)$ and ratios (real divided by imaginary or imaginary divided by real) across the entire frequency spectrum, 20 parameters in total can be generated that act as indicators of specific interfacial change.

The analyzed functions herein were impedance $\left(\mathrm{Z}^{*}\right)$, capacitance $\left(C^{*}\right)$, modulus $\left(\mathrm{M}^{*}\right)$ and admittance $\left(\mathrm{Y}^{*}\right)$ with their phasorial relationships as follows,

$C^{*}=1 / j \omega Z^{*}$

$M^{*}=\omega Z^{*}$

$Y^{*}=j \omega C^{*}$

where $j=\sqrt{-1}$ and $\omega=2 \pi f$.

The responses of each function was systematically evaluated in the form of relative response $(R R)$ at increasing analyte concentration, where $R R_{n}^{f} \%$ is defined as

$$
R R_{n}^{f} \%=\left[\left(R_{n}^{f}-R_{0}^{f}\right) / R_{0}^{f}\right] \times 100
$$

$R_{0}^{f}$ is the blank response, i.e. the antibody receptor interface in the absence of analyte, $R_{n}^{f}$ is the response after incubation with specific target concentration of $n$ at the same frequency $f$.

An in-house written MATLAB R2014b algorithm was used to convert impedimetric data into phasorial related immittance functions and determine the optimal frequency at which the response of 
$\operatorname{Im} F$ is both monotonic and linear $\left(\mathrm{R}^{2}>0.96\right)$. Only those functions and frequencies with optimal sensitivity are taken forward to further analysis. Note that for most $\operatorname{Im} F$ parameters there exists a range of frequencies, around the optimal frequency, for which the sensitivity is largely constant. Consequently a narrow frequency band of $7.5 \pm 2.55 \mathrm{~Hz}$ could be used under such circumstances. Limits of detection (LOD) were calculated, on the basis of the standard deviation $(\delta)$ of the blank response and slope of the analytical curve (sensitivity is defined hereby), as $3.3 \times \delta$ / slope.

\section{Analytical method and justification}

Prior to the analysis of any real or exosomal sample, we initially set out to gauge the reliability of syntenin quantification through the repeat analysis of two pre-prepared "artificial unknown" solutions, $\mathrm{X}$ and $\mathrm{X}^{\prime}$ with concentrations of $80 \mathrm{pM}$ and $50 \mathrm{pM}$ (PBS containing $0.375 \%$ SDS) respectively. These solutions were spiked into recombinant syntenin solutions spanning $0.1-10 \mathrm{nM}$. Standard addition analyses were then used to quantify recovery. Analysis of $20 \mathrm{Im} F$ parameters identified $Z^{\prime \prime}$ (or mathematically equivalent $M^{\prime}$ ) as the most robust predictor, giving both high recovery of $103.0 \%$ and $98.4 \%$ respectively and high precision $(<6 \%$ error, in triplicate repeats on two independent electrodes) over the optimal sampling frequencies of $7.5 \pm 2.55 \mathrm{~Hz}$ (SI, Figure S1).

\section{Results and discussion}

\section{Receptor layer characterization and specificity}

The utilised thiolated polyethylene glycol (PEG) interface presents a nontoxic, hydrophilic biocompatible layer that sufficiently minimises nonspecific protein binding and undesired interactions with lipids on extracellular vesicles. ${ }^{5,23}$ Film formation was associated with an expected increase in (full spectrum) impedance-resolved charge transfer resistance, $R_{C T}$, from $250 \pm 30 \Omega$ (bare gold) to 9 $\pm 0.4 \mathrm{k} \Omega$ (SI, Figure S2). SAM surface coverage was defined by thiol reductive stripping peak $(-1.04$ $\mathrm{V}$ vs. $\mathrm{Ag} / \mathrm{AgCl}$ sat. $\mathrm{KCl}$, deaerated $0.5 \mathrm{M} \mathrm{KOH})$ and displayed a coefficient of variation $<4 \%$ repeated as assessed across 8 independent electrodes. Consequent carbodiimide/succinimide chemistry then enabled covalent tethering of analyte-specific antibody to the film with an associated increase in baseline $R_{C T}$ to $32 \pm 0.2 \mathrm{k} \Omega$ (SI, Figure S2). Each assay commenced only after the 
baseline impedance change in PBS was $<0.2 \%$ to ensure a minimum contribution from nonelectrochemical parameters such as film solubility and wettability. In the absence of antigen such receptive layers exhibited a high stability in PBS (<0.7\% impedance change) over 48 hours at $20 \pm$ $0.2^{\circ} \mathrm{C}$.

Internal proteins need to be released by lysis prior to interfacial immunocapture, ${ }^{32}$ a process which potentially exposes the sensory interface to interfering lipids, growth factors and a raft of other proteins. An initial assessment of film tolerance and retention of assaying specificity under such circumstances was made. A prepared $100 \mathrm{pM}$ recombinant syntenin solution yielded a relative response $\left(R R\left(R_{\mathrm{CT}}\right) \%\right)$ of $46.9 \pm 2.56$. This compares very favourably to nonspecific responses as assessed in serum (which obviously includes a general protein background significantly more challenging to an interface than cell conditioned medium) and depicted in Figure 1. Such high levels of interfacial selectivity demonstrated here is fully in line with previously reported work assessed by either EIS or non-EIS methods. ${ }^{5,23,33}$ More negative controls are shown in supporting information (Figure S3). It was previously reported that sodium dodecyl sulphate (SDS) was more effective in vesicle lysis at low concentrations. ${ }^{32}$ It can be seen in Figure 1 that specific target recognition was fully retained (ca. 85\%) in the presence of SDS across $0.05-0.5 \%$. Additionally, a very minimal perturbation of specific response is observed (see 'Exosomal syntenin assays' section below).

\section{Single step exosome quantification via CD81 interfacial response}

Embryonic kidney HEK293 cell lines serve as a model system to study exosome specific markers. ${ }^{14,26}$ Exosomes were extracted from the supernatant of cell conditioned medium (CCM) via ultrafiltration (see the Experimental section). The extracted exosomes were characterised via both transmission electron microscopy (TEM) and nanoparticle tracking analysis (NTA) (SI, Figure S4), where particle number and diameter were determined to be $(2.4 \pm 0.67) \times 10^{10}$ particles $\mathrm{mL}^{-1}$ and $(73 \pm 8) \mathrm{nm}$ respectively, in line with expectations. ${ }^{5,14}$ To expand the analytical window at the high end for particle numbers by one order of magnitude ultracentrifugation (UC) was applied in generating exosome levels measured to be $(26.2 \pm 3.26) \times 10^{10}$ particles $\mathrm{mL}^{-1}$. UC procedures are innately very time 
consuming (4-5 hours) $)^{17}$ and were applied herein solely to generate exosome samples $>2.4 \times 10^{10}$ particles $\mathrm{mL}^{-1}$. Direct ultrafiltration $(<30$ minutes $)$ was applied in the generation of all other samples.

After this initial preparation, the impedimetric response at anti-CD81 modified films was thereafter used to quantify exosome concentrations. The frequency-specific immittance function $(\operatorname{Im} F)$ based analysis (see Experimental) was used to quantify exosome concentration through the cumulative response at electrode surfaces. Normalised $\operatorname{Im} F$ responses were observed to have a predictably linear correlation with NTA resolved particle concentration (Figure 2) over a 5 decade dynamic range. Note that this dynamic range is both fully in line with that reported in many label free immunoassays $\mathrm{s}^{34,35}$ and in recent ELISA based assessments of exosomal markers. ${ }^{11,19}$ The assay detection limit was determined to be ca. $1.9 \times 10^{5}$ particles $\mathrm{mL}^{-1}$ (equiv. $320 \mathrm{aM}$ ). It is noteworthy that this single step, label free electroanalytical method, is both comparable in sensitivity to a recently reported nanohole plasmonic assay $\left(670 \mathrm{aM}\right.$ or $4.0 \times 10^{5}$ particles $\left.\mathrm{mL}^{-1}\right),{ }^{5}$ and to that reported by signal-augmented labelling methods, including electrochemical sandwich immunosensors $\left(2.0 \times 10^{5} \text { particles } \mathrm{mL}^{-1}\right)^{36}$ and ExoSearch chips $\left(7.5 \times 10^{5}\right.$ particles $\left.\mathrm{mL}^{-1}\right) .{ }^{11}$ Note also that the LOD is some $10^{4}$-fold lower than that associated with Western blot analyses. ${ }^{13}$

\section{Exosomal syntenin assays}

Recombinant syntenin assays were first carried out in the absence of potential interferents. Imaginary impedance $\left(Z^{\prime \prime}\right.$ or mathematically equivalent real part of modulus $\left.-M^{\prime}\right)$ was derived to be optimal among 20 generic electrical transfer functions (SI, Figure S5) and its relative response $\left(R R\left(Z^{\prime \prime}\right.\right.$ or $\left.\left.M^{\prime}\right) \%\right)$ to syntenin across a full frequency range was shown in Figure 3. An analytical curve optimal at $10 \mathrm{~Hz}$ is depicted in Figure 3 inset, highlighting a linear range of $50 \mathrm{pM}-200 \mathrm{nM}$ $\left(\mathrm{R}^{2}>0.99\right)$. The assay LOD and sensitivity were $1.3 \pm 0.25 \mathrm{pM}$ and $31.6 \pm 4.01 \%$ conc $^{-1}$ respectively, summarised in Table 1, as assessed through triplicate repeats across at least three independent electrodes. A Langmuir adsorption isotherm resolved dissociation constant $\left(K_{\mathrm{D}}\right)^{37}$ being $(1.7 \pm 0.05) \times$

$10^{-9} \mathrm{M}$ lies towards the lower end of prior reported $K_{\mathrm{D}}$ assessments for syntenin- $1,,^{38,39}$ and is indicative of a high interfacial binding affinity. 
Standard recombinant syntenin solutions were then spiked with potential relevant interferents, namely $10 \%$ human serum (PBST $-0.1 \%$ Tween 20 ) and $0.375 \%$ SDS (the latter was used as the lysis buffer). The $Z^{\prime \prime}$ function remained the most potent reporter of specific interfacial recognition and the optimal calibration curves were shown in Figure 4(a) and (b). Assay sensitivities, dynamic ranges, LOD and resolved $K_{D}$ are pleasingly retained (Table1).

To now set about determining unknown exosomal syntenin, recombinant protein solutions were spiked with isolated exosomes and analysed under both non-lysed (intact exosome) and lysed conditions (see standard addition curves Figure 4(c) and (d)). A box plot of determined exosomal syntenin levels is depicted in Figure 5, where standard addition method (see Experimental) was applied. Recombinant syntenin dissolved in pure PBS and lysis buffer in the absence of intrinsic exosomes were used as controls. It can be seen that under non-lysed conditions interfacial responses are well within the background response. Very significant interfacial responses are observed only on lysing, where, in these samples ca. $3 \times 10^{11}$ particles $\mathrm{mL}^{-1}$ were spiked into recombinant syntenin solutions, resolved exosomal syntenin level was ca. $(580+332 /-248)$ pM. To the best of our knowledge this is the first time that ultrasensitive detection of syntenin is achieved from lysed exosomes. Though a number of previous reports of exosomal syntenin detection in human serum and cell conditioned medium exist, ${ }^{16,28,40}$ none have previously been able to resolve concentrations approaching those measured herein.

\section{Normalised exosomal syntenin}

Once a sensitive and selective assessment of both total exosome count (through interfacial tetraspanin response) and internal syntenin is possible it then becomes straightforward to normalise any assessment of an internal marker for sample preparation (something which can generate exosome concentrations spanning many orders of magnitude with appreciable batch to batch variance). Herein we have normalised all syntenin quantifications for exosome count without any prior requirement for an ex situ NTA analysis. For any detected exosomal syntenin concentration, there is a simultaneously correlating CD81 response that directly relates to the number of particles being present. Since these impedimetric assays can be run in a matter of minutes, a stepwise exosomal determination, lysis and 
internal-marker determination is facile. Figure 6 demonstrated the normalised exosomal syntenin concentrations from cell conditioning media isolated exosomes (both exosome and internal marker quantifications in triplicate). Note that exosomal syntenin level became undetectable below ca. $10^{9}$ particles $\mathrm{mL}^{-1}$. Significantly, such dual marker analyses enable the construction of defined 'analytical zones' in a manner which is then independent of absolute exosome concentration/isolation history.

\section{Conclusion}

Herein we have applied highly sensitive and label free electrochemical impedimetric analysis to the quantification of both external (tetraspanin) and internal (syntenin) exosome-specific markers. Exosomes isolated through a rapid fine sample filtration produced interfacial responses upon intact exosome capture that are highly specific and linear over five orders of magnitude particle numbers. The associated exosome detection limit is $1.9 \times 10^{5}$ particles $\mathrm{mL}^{-1}$ (equiv. to $320 \mathrm{aM}$ or 9500 exosomes in $50 \mu \mathrm{L}$ ); internalised syntenin could be reliably quantified, on lysing, down to $3-5$ picomolar level with almost 5 decades of linear dynamic range. Since these impedimetric assays are facile, it is possible to sequentially determine exosome concentration immediately prior to lysing and subsequent internal syntenin analysis without any reference to ex situ NTA analysis. Such dualmarker analysis can be used to define 'analytical zones' in a manner which is then independent of absolute exosome concentration and sample preparation. The above methodology can be reliably rolled out across a very broad range of possible indicators with a convenience that we believe surpasses that of prior work. This approach lays a foundation for the ex situ on-chip normalised simultaneous electroanalysis of a range of exosomal markers in normal and disease bio-samples with high levels of sensitivity.

\section{Acknowledgement}

We thank Dr Errin Johnson for TEM data acquisition. This work was funded by an EPSRC project grant (EP/M006204/1) to G.K.T and J.J.D. 


\section{Supporting Information}

A summary of ImF characteristics, interfacial characterisation data, assay selectivity data and exosome characterisation data. This material is available free of charge via the Internet at http:// pubs.acs.org.

\section{References}

(1) Colombo, M.; Raposo, G.; Théry, C. Annu. Rev. Cell Dev. Biol 2014, 30, 255-289.

(2) Vlassov, A. V.; Magdaleno, S.; Setterquist, R.; Conrad, R. Biochim. Biophys. Acta 2012, 1820 (7), 940-948.

(3) Théry, C.; Ostrowski, M.; Segura, E. Nat. Rev. Immunol. 2009, 9 (8), 581-593.

(4) Franzen, C. A.; Blackwell, R. H.; Foreman, K. E.; Kuo, P. C.; Flanigan, R. C.; Gupta, G. N. J. Urol. 2016, 195 (5), 1331-1339.

(5) Im, H.; Shao, H.; Park, Y. Il; Peterson, V. M.; Castro, C. M.; Weissleder, R.; Lee, H. Nat. Biotechnol. 2014, 32 (5), 490-495.

(6) Melo, S. A.; Luecke, L. B.; Kahlert, C.; Fernandez, A. F.; Gammon, S. T.; Kaye, J.; Lebleu, V. S.; Mittendorf, E. a.; Weitz, J.; Rahbari, N.; Reissfelder, C.; Pilarsky, C.; Fraga, M. F.; Piwnica-Worms, D.; Kalluri, R. Nature 2015, 523 (7559), 177-182.

(7) Taller, D.; Richards, K.; Slouka, Z.; Senapati, S.; Hill, R.; Go, D. B.; Chang, H.-C. Lab Chip 2015, 15 (7), 1656-1666.

(8) Nilsson, J.; Skog, J.; Nordstrand, A.; Baranov, V.; Mincheva-Nilsson, L.; Breakefield, X. O.; Widmark, A. Br. J. Cancer 2009, 100 (10), 1603-1607.

(9) Zhou, Y. G.; Mohamadi, R. M.; Poudineh, M.; Kermanshah, L.; Ahmed, S.; Safaei, T. S.; Stojcic, J.; Nam, R. K.; Sargent, E. H.; Kelley, S. O. Small 2015, No. 6, 727-732.

(10) Welton, J. L.; Khanna, S.; Giles, P. J.; Brennan, P.; Brewis, I. a; Staffurth, J.; Mason, M. D.; Clayton, A. Mol. Cell. Proteomics 2010, 9 (6), 1324-1338.

(11) Zhao, Z.; Yang, Y.; Zeng, Y.; He, M. Lab Chip 2015, 16, 489-496.

(12) Stern, E.; Vacic, A.; Rajan, N. K.; Criscione, J. M.; Park, J.; Fahmy, T. M.; Reed, M. A. ICSICT-2010 - 2010 10th IEEE Int. Conf. Solid-State Integr. Circuit Technol. Proc. 2010, 5 (2), 1392-1393.

(13) Shao, H.; Chung, J.; Balaj, L.; Charest, A.; Bigner, D. D.; Carter, B. S.; Hochberg, F. H.; Breakefield, X. O.; Weissleder, R.; Lee, H. Nat. Med. 2012, 18 (12), 1835-1840.

(14) Jeppesen, D. K.; Hvam, M. L.; Primdahl-Bengtson, B.; Boysen, A. T.; Whitehead, B.; Dyrskjøt, L.; Orntoft, T. F.; Howard, K. A.; Ostenfeld, M. S. J. Extracell. vesicles 2014, 3, 25011.

(15) Kowal, J.; Arras, G.; Colombo, M.; Jouve, M.; Morath, J. P.; Primdal-Bengtson, B.; Dingli, F.; Loew, D.; Tkach, M.; Théry, C. Proc. Natl. Acad. Sci. 2016, 113 (8), E968-77. 
(16) Baietti, M. F.; Zhang, Z.; Mortier, E.; Melchior, A.; Degeest, G.; Geeraerts, A.; Ivarsson, Y.; Depoortere, F.; Coomans, C.; Vermeiren, E.; Zimmermann, P.; David, G. Nat. Cell Biol. 2012, 14 (7), 677-685.

(17) Liga, A.; Vliegenthart, A. D. B.; Oosthuyzen, W.; Dear, J. W.; Kersaudy-Kerhoas, M. Lab Chip 2015, 15 (11), 2388-2394.

(18) He, M.; Crow, J.; Roth, M.; Zeng, Y.; Godwin, A. K. Lab Chip 2014, 3773-3780.

(19) Zhang, P.; He, M.; Zeng, Y. Lab Chip 2016, No. 16, 3033-3042.

(20) Grasso, L.; Wyss, R.; Weidenauer, L.; Thampi, A.; Demurtas, D.; Prudent, M.; Lion, N.; Vogel, H. Anal. Bioanal. Chem. 2015, 5425-5432.

(21) Rupert, D. L. M.; Lässer, C.; Eldh, M.; Block, S.; Zhdanov, V. P.; Lotvall, J.; Bally, M.; Höök, F. Anal. Chem. 2014, 86, 5929-5936.

(22) Luo, X.; Davis, J. J. Chem. Soc. Rev. 2013, 42 (13), 5944-5962.

(23) Luo, X.; Xu, Q.; James, T.; Davis, J. J. Anal. Chem. 2014, 86 (11), 5553-5558.

(24) Koo, T. H.; Lee, J. J.; Kim, E. M.; Kim, K. W.; Kim, H. Do; Lee, J. H. Oncogene 2002, 21 (26), 4080-4088.

(25) Pardo, M.; García, Á.; Antrobus, R.; Blanco, M. J.; Dwek, R. A.; Zitzmann, N. J. Proteome Res. 2007, 6 (7), 2802-2811.

(26) Dasgupta, S.; Menezes, M. E.; Das, S. K.; Emdad, L.; Janjic, A.; Bhatia, S.; Mukhopadhyay, N. D.; Shao, C.; Sarkar, D.; Fisher, P. B. Clin. Cancer Res. 2013, 19 (17), 4621-4633.

(27) Chiasserini, D.; Van Weering, J. R. T.; Piersma, S. R.; Pham, T. V.; Malekzadeh, A.; Teunissen, C. E.; De Wit, H.; Jiménez, C. R. J. Proteomics 2014, 106, 191-204.

(28) Tomlinson, P. R.; Zheng, Y.; Fischer, R.; Heidasch, R.; Gardiner, C.; Evetts, S.; Hu, M.; Wade-Martins, R.; Turner, M. R.; Morris, J.; Talbot, K.; Kessler, B. M.; Tofaris, G. K. Ann. Clin. Transl. Neurol. 2015, 2 (4), 353-361.

(29) Witwer, K. W.; Buzás, E. I.; Bemis, L. T.; Bora, A.; Lässer, C.; Lötvall, J.; Nolte-’t Hoen, E. N.; Piper, M. G.; Sivaraman, S.; Skog, J.; Théry, C.; Wauben, M. H.; Hochberg, F. J. Extracell. vesicles 2013, 2, 1-25.

(30) Hideshima, S.; Sato, R.; Inoue, S.; Kuroiwa, S.; Osaka, T. Sensors Actuators B Chem. 2012, 161 (1), 146-150.

(31) Patil, A. V.; Bedatty Fernandes, F. C.; Bueno, P. R.; Davis, J. J. Anal. Chem. 2015, 87 (2), 944-950.

(32) Osteikoetxea, X.; Sódar, B.; Németh, A.; Szabó-Taylor, K.; Pálóczi, K.; Vukman, K. V.; Tamási, V.; Balogh, A.; Kittel, Á.; Pállinger, É.; Buzás, E. I. Org. Biomol. Chem. 2015, 13 (38), 9775-9782.

(33) Xu, M.; Luo, X.; Davis, J. J. Biosens. Bioelectron. 2013, 39 (1), 21-25.

(34) Sharma, R.; Deacon, S. E.; Nowak, D.; George, S. E.; Szymonik, M. P.; Tang, A. A. S.; Tomlinson, D. C.; Davies, A. G.; McPherson, M. J.; Wälti, C. Biosens. Bioelectron. 2016, 80, 607-613.

(35) Klukova, L.; Filip, J.; Belicky, S.; Vikartovska, A.; Tkac, J. Analyst 2016, 141 (14), 42784282. 
(36) Ximena Doldán, Pablo Fagúndez, Alfonso Cayota, Justo Laíz, J. P. T. Anal. Chem. 2016, 88 (21), 10466-10473.

(37) Fernandes, F. C. B.; Santos, A.; Martins, D. C.; Goes, M. S.; Bueno, P. R. Biosens. Bioelectron. 2014, 57, 96-102.

(38) Kang, B. S.; Cooper, D. R.; Jelen, F.; Devedjiev, Y.; Derewenda, U.; Dauter, Z.; Otlewski, J.; Derewenda, Z. S.; York, N. 2003, 11 (3), 459-468.

(39) Latysheva, N.; Muratov, G.; Rajesh, S.; Padgett, M.; Hotchin, N. A.; Overduin, M.; Berditchevski, F. Mol. Cell. Biol. 2006, 26 (20), 7707-7718.

(40) Ghossoub, R.; Lembo, F.; Rubio, A.; Gaillard, C. B.; Bouchet, J.; Vitale, N.; Slavík, J.; Machala, M.; Zimmermann, P. Nat. Commun. 2014, 5, 3477.

\section{Figures and tables}

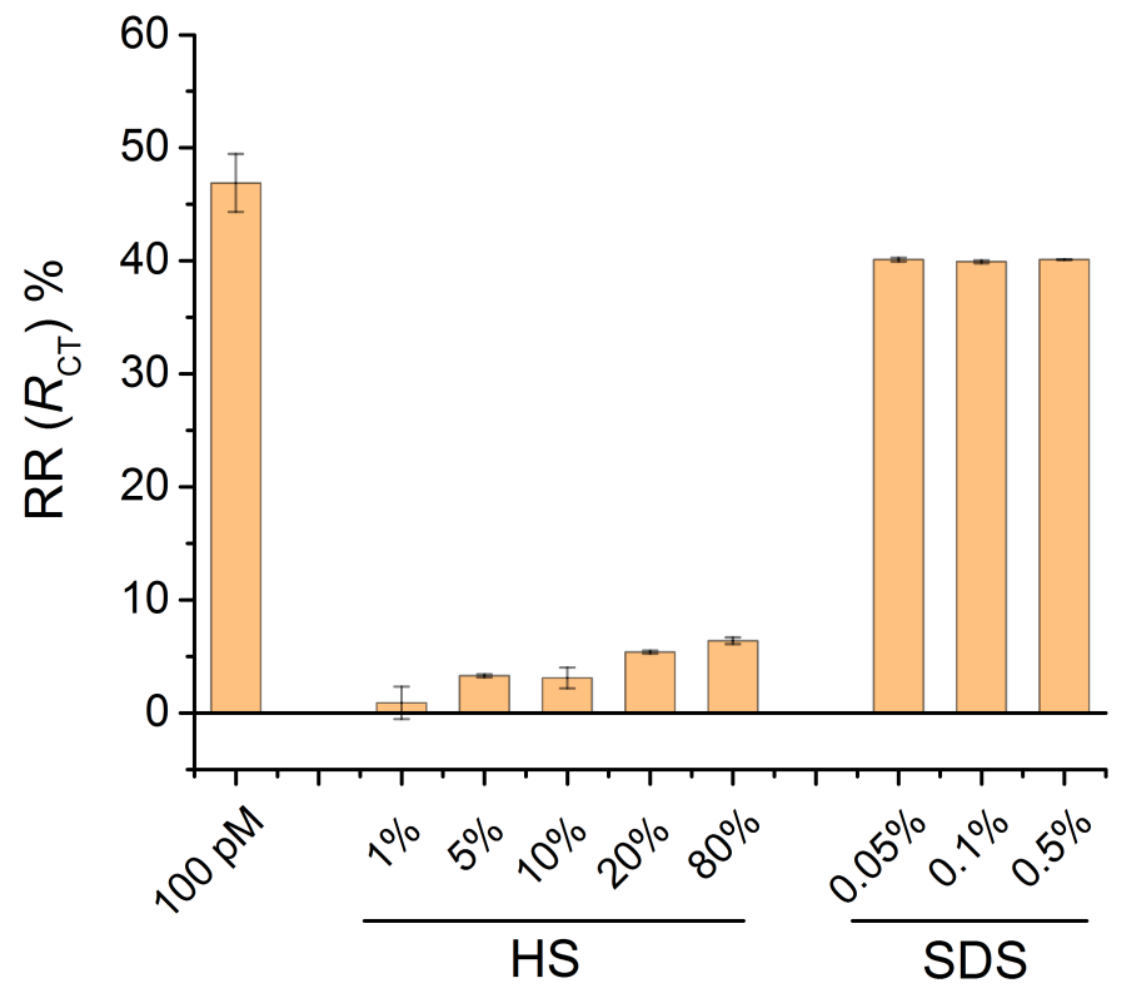

Figure 1: Receptor layer specificity on exposure to human serum and lysing lipids. A specific response with low analyte concentration of $100 \mathrm{pM}$ recombinant syntenin/PBS is shown for comparison. Antibody interfaces were exposed sequentially to diluted human serum in PBST $(0.1 \%$ Tween20, v:v) from 1 to $80 \%$. Additionally, specific target recognition (100 pM) was fully retained (ca. 85\%) in the presence of ionic detergent SDS across $0.05-0.5 \%$ (v:v). Error bars were generated from nine measurements across three electrodes. Note that this figure serves solely to highlight the high levels of interfacial selectivity achieved herein as being fully in line with previous work by us and others. ${ }^{5,23,33}$ All exosomal analyses were carried out with samples isolated from cell conditioned medium. 


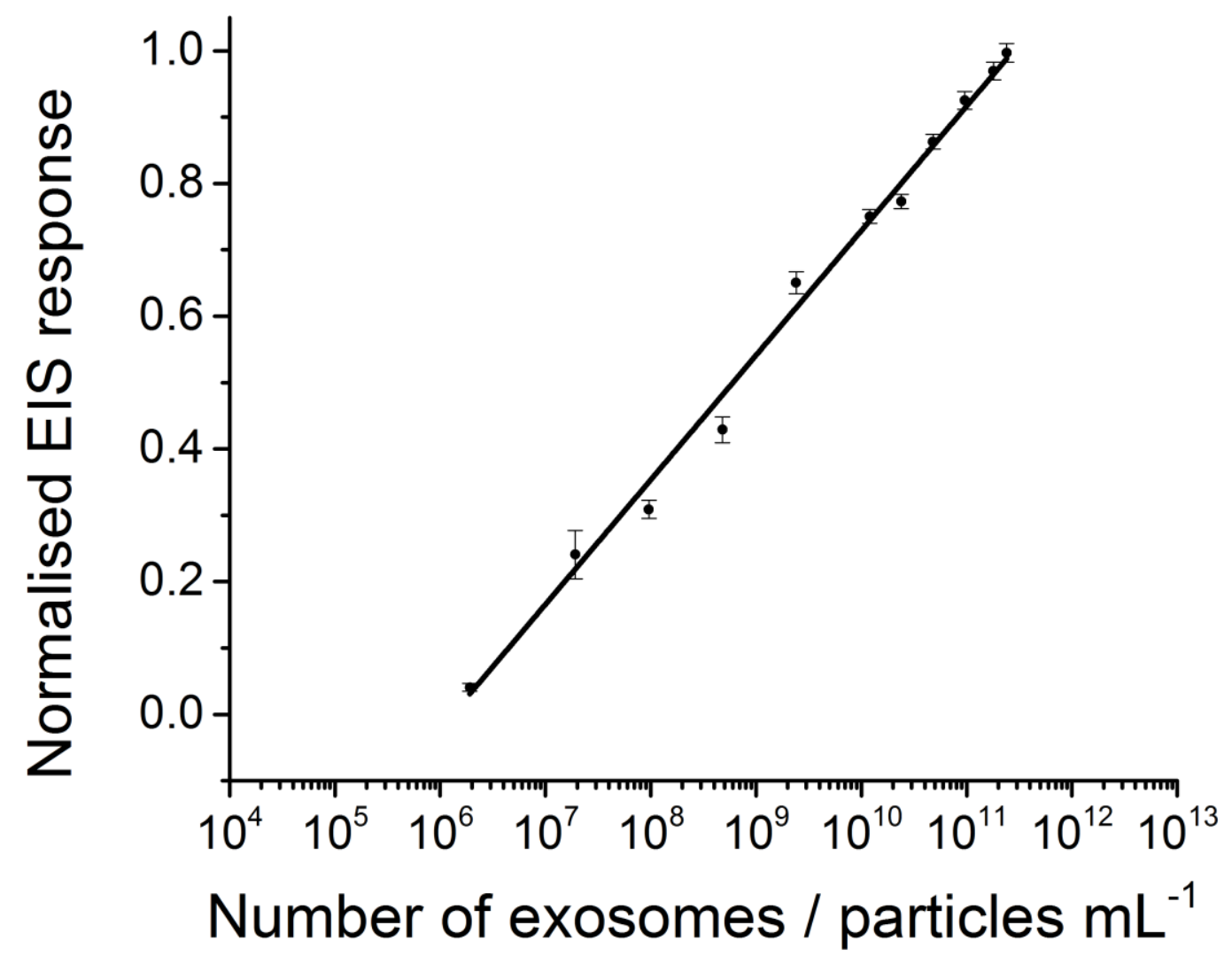

Figure 2: Electroanalytical exosome quantification through CD81 response and comparison to NTA. All responses were normalised against the maximum response (linear regression $\mathrm{R}^{2}>0.98$ ). The assay detection limit was determined to be ca. $1.9 \times 10^{5}$ particles $\mathrm{mL}^{-1}$ (equiv. $320 \mathrm{aM}$ or 9600 exosomes in $50 \mu \mathrm{L})$. Error bars generated from triplicate repeats across 3 independent electrodes. 


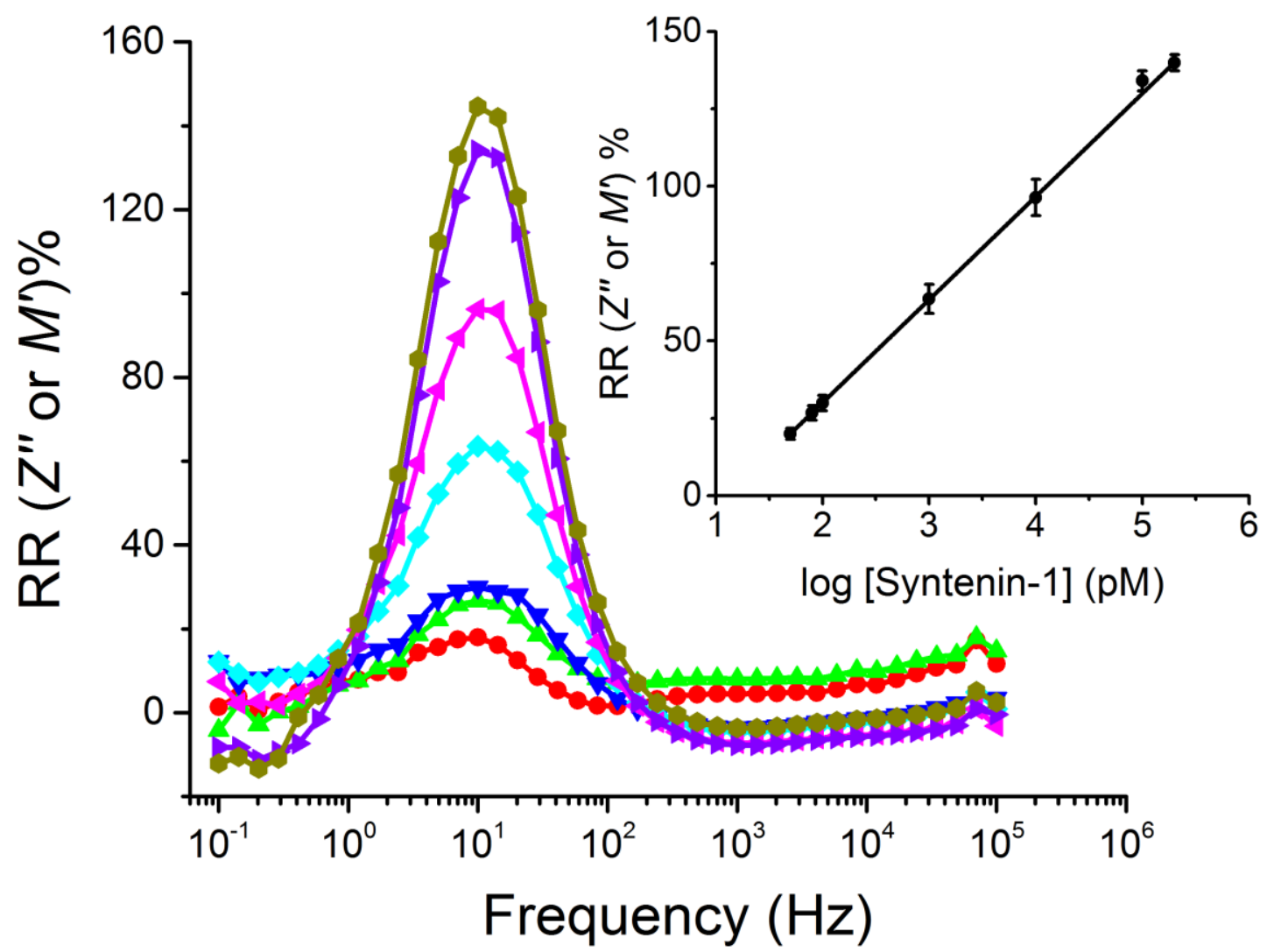

Figure 3: Relative response of immittance function $Z^{\prime \prime}$ (or mathematically equivalent $M^{\prime}, R R\left(Z^{\prime \prime}\right.$ or $\left.\left.M^{\prime}\right) \%\right)$ analyzed across a frequency range of $0.1-100 \mathrm{kHz}$ at increasing recombinant syntenin-1 from $50 \mathrm{pM}-200 \mathrm{nM}$ in PBS (in the absence of interferents). Inset shows the calibration curve at $10 \mathrm{~Hz}$ being linear across over 5 orders of magnitude, $\mathrm{R}^{2}>0.99$. 




Figure 4: Recombinant syntenin-1 assays show consistent LODs and dynamic ranges in the presence of potential interferents (a) 10\% human serum (PBST - 0.1\% Tween20) and (b) 0.375\% SDS; and with spiked exosomes (ca. $3 \times 10^{11}$ particles $\mathrm{mL}^{-1}$ ) to recombinant protein solutions at (c) non-lysing and (d) lysing conditions. The extended calibration curves at $R R$ being zero in both (c) and (d) represent the detected exosomal syntenin via standard addition method. Calibration curves were at their most responsive frequencies $(7.5 \pm 2.55) \mathrm{Hz}$ with $\mathrm{R}^{2}>0.96$, optimised and represented by $R R\left(Z^{\prime \prime}\right.$ or $\left.M^{\prime}\right) \%$. 


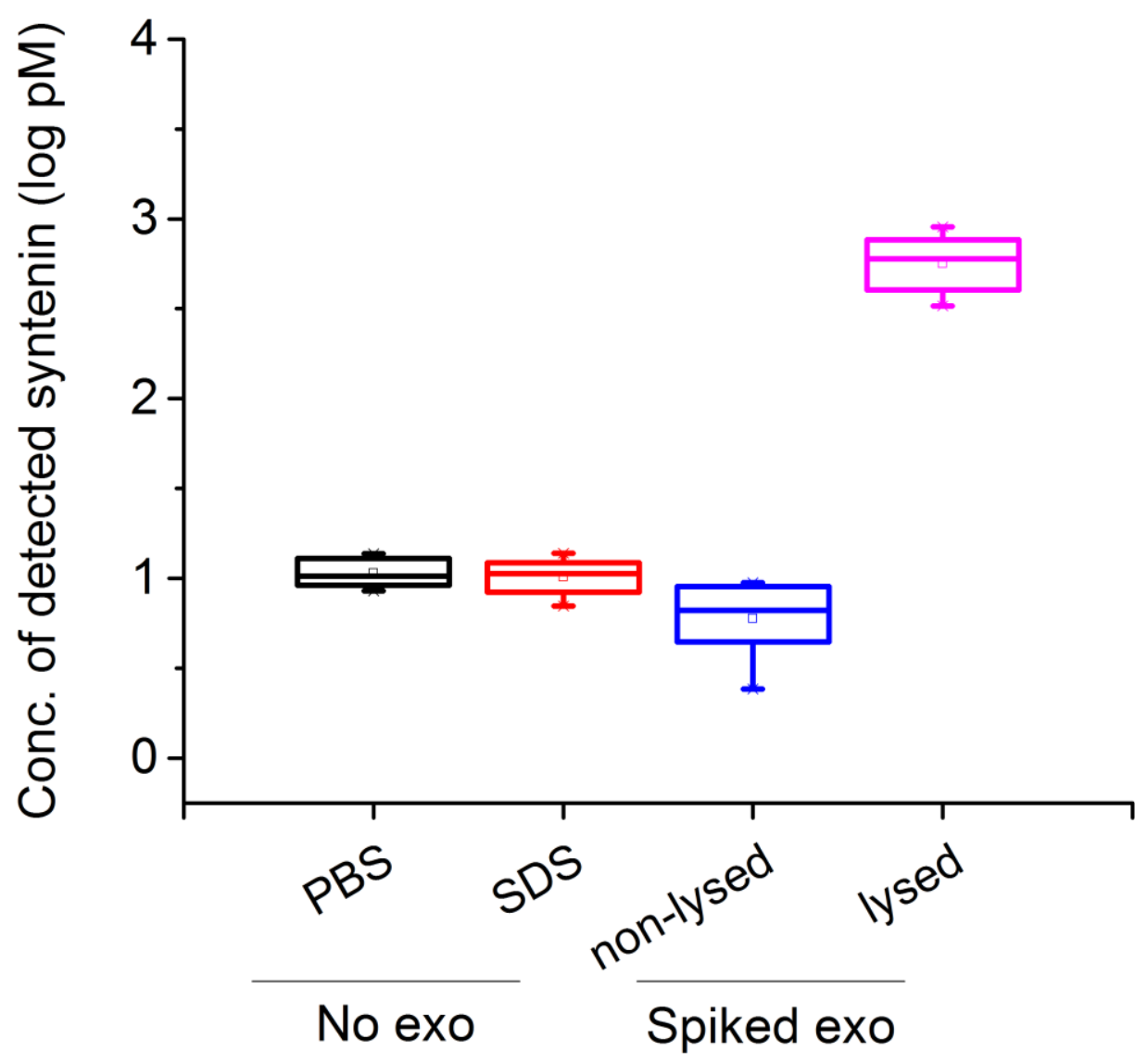

Figure 5: Box plots reflecting the distribution $(n=8)$ of detected exosomal syntenin concentrations under specific conditions: both pure PBS and SDS-spiked solutions are exosome-free; both non-lysed and lysed samples were spiked with exosomes of ca. $3 \times 10^{11}$ particles $\mathrm{mL}^{-1}$. The box bounds the IQR divided by the mean, the median and whiskers extend to a maximum of $1.5 \times$ IQR beyond. The box width is scaled to $\sqrt{n}$. Each sample was measured in triplicate across three independent electrodes. The associated errors are less than $6 \%$ at any specific frequency. The statistical difference between the group means, as assessed by ANOVA was $\mathrm{F}(3,28)=5075.928, p<0.01$. 


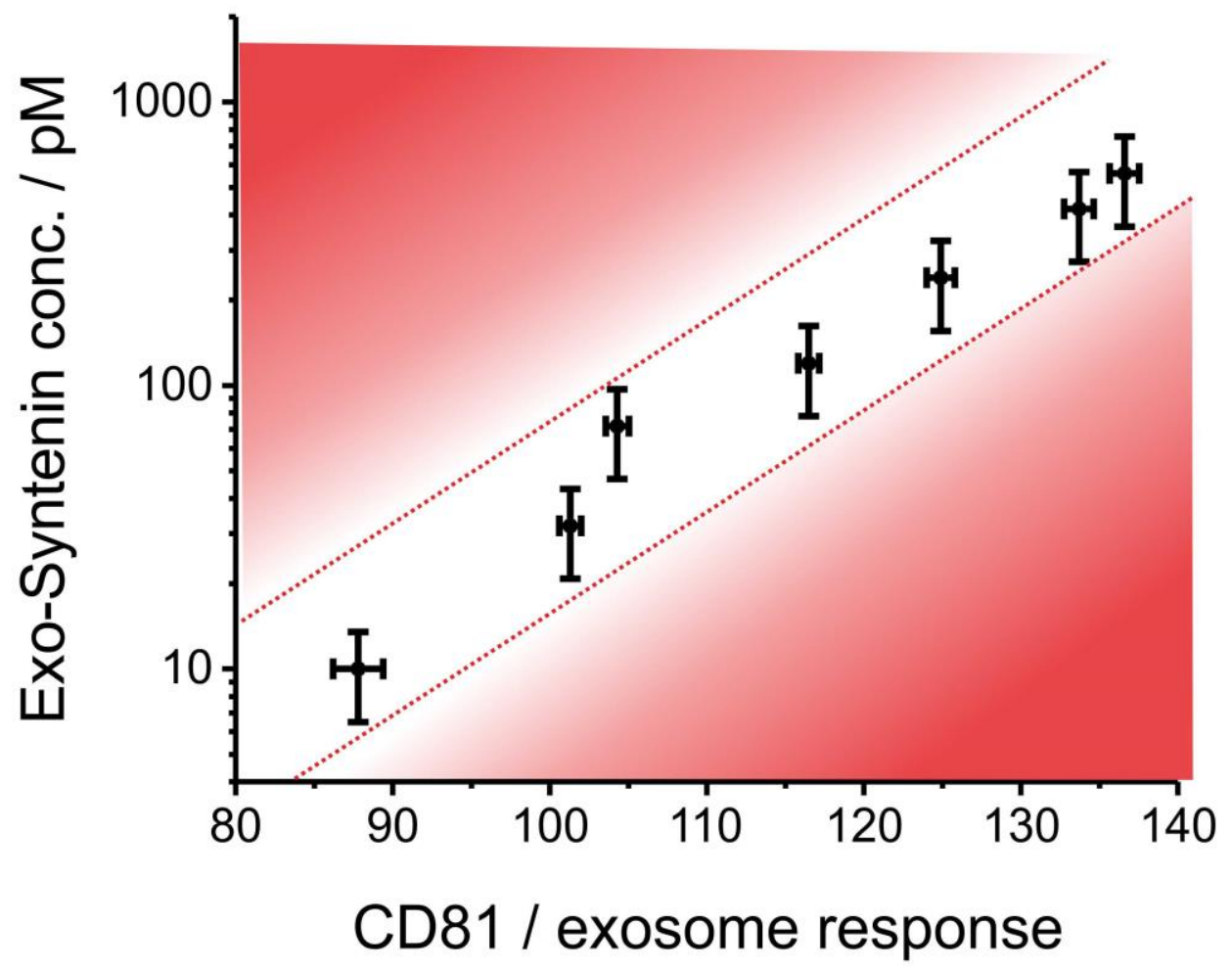

Figure 6: Normalised electroanalytical exosomal syntenin quantification against intact exosome responses (CD81 response). Such a dual marker correlation can be used to define 'analytical zones' where, for example, different patient samples/disease states night be distinguishable. Note that normalised data are shown above ca. $10^{9}$ particles $\mathrm{mL}^{-1}$, below which level exosomal syntenin are undetectable. The dynamic range, over which syntenin can be reliably quantified, spans almost 3 decades of particle concentration. 
Table $1 \operatorname{Im} F$ parameter $\left(\boldsymbol{Z}^{\prime \prime}\right.$ or $\left.\boldsymbol{M}^{\prime}\right)$ responses for spiked recombinant syntenin assays under five different conditions as measured at optimal sampling frequencies at $(7.5 \pm 2.55) \mathrm{Hz}$. All data points were based upon at least 3 electrodes with 3 repetitions per concentration. Sensitivity, LOD and dissociation constant $\left(K_{\mathrm{D}}\right)$ were calculated by averaging linear fits on 3 electrodes to averaged relative response across the repetitions.

\begin{tabular}{|c|c|c|c|c|}
\hline $\begin{array}{c}\text { Spiked } \\
\text { recombinant } \\
\text { syntenin-1 assays }\end{array}$ & $\mathrm{R}^{2}$ & $\begin{array}{c}\text { Sensitivity } \\
\left(\% \text { conc }^{-1}\right)\end{array}$ & $\begin{array}{c}\text { LOD } \\
(\mathrm{pM})\end{array}$ & $\begin{array}{c}K_{\mathrm{D}} \\
(\mathrm{nM})\end{array}$ \\
\hline \multicolumn{5}{|c|}{ No exosome } \\
\hline $\begin{array}{c}\text { Pure PBS } \\
\begin{array}{c}\text { HS }-10 \% \text { PBST } \\
-0.1 \%\end{array}\end{array}$ & 0.99 & $31.6 \pm 4.01$ & $1.3 \pm 0.25$ & $1.7 \pm 0.05$ \\
\hline $\begin{array}{c}\text { SDS - 0.375\% / } \\
\text { PBS }\end{array}$ & 0.99 & $31.7 \pm 3.32$ & $3.8 \pm 1.55$ & $1.1 \pm 0.06$ \\
\hline \multicolumn{5}{|c|}{ Spiked exosomes } \\
\hline Non-lysed & 0.98 & $42.8 \pm 2.76$ & $3.2 \pm 0.71$ & $1.8 \pm 0.05$ \\
\hline Lysed & 0.96 & $44.6 \pm 1.1$ & $4.5 \pm 1.14$ & - \\
\hline
\end{tabular}




\section{For TOC only}

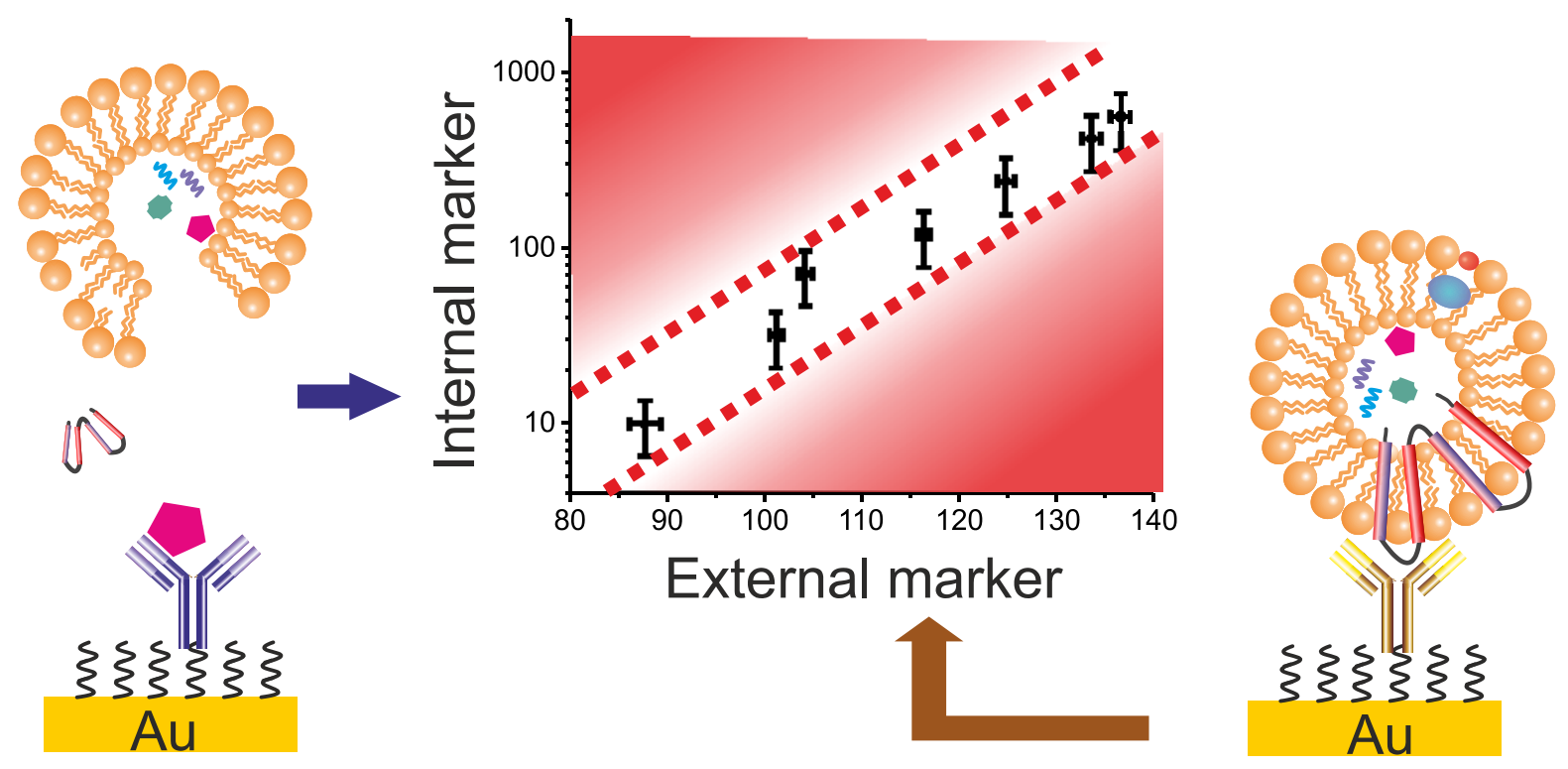

